\title{
Diagnostic value of triggering receptor expressed on myeloid cells-1 and C-reactive protein for patients with lung infiltrates: an observational study
}

llias Porfyridis ${ }^{1 *}$, Diamantis Plachouras ${ }^{2 \dagger}$, Vasiliki Karagianni ${ }^{2 \dagger}$, Anastasia Kotanidou $^{1 \dagger}$, Spyridon A Papiris $^{3 \dagger}$, Helen Giamarellou ${ }^{2 \dagger}$, Evangelos J Giamarellos-Bourboulis ${ }^{2+}$

\begin{abstract}
Background: Differential diagnosis of patients with lung infiltrates remains a challenge. Triggering receptor expressed on myeloid cells (TREM)- 1 is a neutrophil and monocyte receptor up-regulated during infection. The aim of this study was to evaluate the diagnostic accuracy of TREM-1 and of C-reactive protein (CRP) from patients with lung infiltrates to discern community acquired lung infections.

Methods: 68 patients admitted to a medical ward with acute respiratory illness were enrolled in the study. Neutrophil and monocyte TREM-1 expression were measured by flow cytometry, sTREM-1 by an enzyme immunoassay and C-reactive protein by nephelometry. Clinical pulmonary infection score was recorded.

Results: 34 patients were diagnosed with bacterial community acquired pneumonia (group A) and 34 with nonbacterial pulmonary disease (group B). Median serum TREM-1 concentration was $102.09 \mathrm{pg} / \mathrm{ml}$ in group A and lower than $15.10 \mathrm{pg} / \mathrm{ml}(\mathrm{p}<0.0001)$ in group B. Mean \pm SE neutrophil TREM-1 expression was $4.67 \pm 0.53 \mathrm{MFI}$ in group $A$ and $2.64 \pm 0.25 \mathrm{MFI}(p=0.001)$ in group B. Monocyte TREM-1 expression was $4.2 \pm 0.42 \mathrm{MFI}$ in group A and $2.64 \pm 0.35 \mathrm{MFI}(p=0.007)$ in group $B$ and mean \pm SE CRP was $18.03 \pm 2 \mathrm{mg} / \mathrm{ml}$ in group $A$ and $7.1 \pm 1.54$ $\mathrm{mg} / \mathrm{ml}(\mathrm{p}<0.001)$ in group B. A cut-off of $19.53 \mathrm{pg} / \mathrm{ml}$ of sTREM-1 with sensitivity $82.6 \%$ and specificity $63 \%$ to discriminate between infectious and non-infectious pulmonary infiltrates was found. sTREM-1 at admission greater than $180 \mathrm{pg} / \mathrm{ml}$ was accompanied with unfavourable outcome.
\end{abstract}

Conclusion: TREM-1 myeloid expression and STREM-1 are reliable markers of bacterial infection among patients with pulmonary infiltrates; sTREM-1 is a predictor of final outcome.

\section{Background}

Early diagnosis of lung infections remains a challenge. There is no gold standard for diagnosing microbial infection as clinical and laboratory signs are neither sensitive nor specific enough, and microbiological studies often remain negative. The presence of a new infiltrate on plain chest radiograph is considered indicative for diagnosing pneumonia, especially when is supported by clinical and laboratory findings. However it is difficult to

\footnotetext{
* Correspondence: ilias_porfi@yahoo.gr

+ Contributed equally

'Department of Critical Care and Pulmonary Services, National and

Kapodistrian University of Athens, 'Evangelismos' Hospital, Athens, Greece Full list of author information is available at the end of the article
}

differentiate a chest infiltrate of bacterial origin from a chest infiltrate of non-bacterial origin solely based on radiological criteria [1]. The diagnosis of infection is not always clear in the acute setting in patients with respiratory tract disease and a surrogate marker of infection would be a major benefit in the diagnostic armamentarium. Many inflammatory mediators and acute phase reactants, like C-reactive protein (CRP) and procalcitonin, have been described as reliable markers of infection; however none are specific enough, since they are also increased in non-infectious inflammatory conditions [2].

Triggering receptor expressed on myeloid cells (TREM)- 1 is a recently described receptor on 
neutrophils and monocytes. It behaves like a pattern recognition receptor (PRR) since its activation leads to the release of pro-inflammatory cytokines, namely of tumour necrosis factor-alpha (TNF $\alpha$ ) and of interleukin (IL)-8. Although its ligand is still unknown, activation is mediated by bacteria and fungi $[3,4]$. A soluble form of TREM-1, namely sTREM-1, is increased in the bronchoalveolar lavage (BAL) of patients with ventilator associated pneumonia (VAP) [5,6], and in the serum of patients with sepsis, with bacterial meningitis and with acute pancreatitis [7-12]. This same soluble form of TREM-1 seems to be increased in patients bearing noninfectious processes like peptic ulcer, inflammatory bowel disease, viral infections, malignant pleural effusions and chronic obstructive pulmonary disease (COPD) but also among patients after cardiac surgery or cardiac arrest. Increase of sTREM-1 seems particular prominent when the latter non-infectious states are complicated with systemic inflammatory response syndrome (SIRS) without infection [13-19].

Several published studies yielded contradictory results for the diagnostic and prognostic usefulness of TREM-1 and of sTREM-1 for infections [5,7,20-22]. The created impression is that more data are necessary to yield definitive results for its usefulness as a diagnostic and prognostic marker of community acquired pneumonia (CAP).

The aim of the present study was to define whether expression of TREM-1 on cell membranes of neutrophils (nTREM-1), of monocytes (mTREM-1) and serum sTREM-1 may help in the diagnosis of acute bacterial infections for patients admitted with a new pulmonary infiltrate or pleural effusion.

\section{Methods}

\section{Study design}

In this observation trial, all consecutive admissions to the Department of Critical Care and Pulmonary Services on predetermined and randomly selected emergency duty days were eligible. Inclusion criteria were: i) age above 16 yrs, ii) written informed consent; iii) acute respiratory illness and iii) presence of new pulmonary infiltrates or pleural effusion on chest $\mathrm{x}$-ray or lung computed tomography. Exclusion criteria were: i) Human immunodeficiency virus (HIV) infection, ii) documented extrapulmonary infection, iii) neutropenia; and iv) oral intake of corticosteroids defined as any more than $1 \mathrm{mg} / \mathrm{kg}$ of prednisone for more than 1 month. The study protocol was approved by the Ethics Committee of the hospital and written informed consent was obtained from all patients within the first $12 \mathrm{hrs}$ after admission.

Clinical, laboratory, and imaging data were recorded for each patient including: i) clinical presentation; ii) body temperature, iii) arterial blood gas, iv) peripheral blood cell counts, v) gram stains and cultures of all biological fluids obtained (blood, sputum, bronchial secretions, BAL, and pleural fluid); vi) imaging findings, vii) antigen serology (Legionella spp and Streptococcus pneumonia urinary antigen, serological testing for Legionella pneumophila, Mycoplasma pneumoniae, Chlamydia pneumoniae) and viii) in-hospital mortality. The severity of illness was assessed by calculating Acute Physiology and Chronic Health Evaluation (APACHE) II, Sequential Organ Failure Assessment (SOFA) and Clinical Pulmonary Infection (CPIS) scores at admission [23].

A diagnosis of community-acquired pneumonia (CAP) was established in any patient presenting with a combination of fever, cough and purulent sputum, shortness of breath, chest pain, and new consolidation on chest $\mathrm{X}$-ray or computed tomography. The severity of pneumonia was assessed the first 24 hours of admission according to Confusion, Urea nitrogen, Respiratory rate, Blood pressure (CURB) index. Patients having two or more criteria were identified to have severe pneumonia [24]. Sepsis, severe sepsis and septic shock were defined according to current recommendations [25]. Pneumonia was considered to be absent when: i) an alternative cause for pulmonary infiltrate was established (e.g. pulmonary embolus) and ii) full recovery was achieved without antimicrobial therapy.

Pulmonary embolism was diagnosed according to current recommendations [26]. Lung cancer was ruled out based on histology and/or cytology specimens. Congestive heart failure was diagnosed according to American Heart Association [27], and interstitial lung disease according to American Thoracic Society guidelines [28]. All cases were evaluated by two clinicians blinded to TREM-1 and sTREM-1 results. Agreement about the diagnosis was achieved in all cases.

Patients with CAP were classified as having bacterial respiratory infection (group A). All other patients were classified as having non-bacterial respiratory disorders (group B). All patients assigned to group B were subject to chest computed tomography.

\section{Laboratory investigation}

For the measurement of sTREM-1, mTREM-1, nTREM1 and CRP $10 \mathrm{ml}$ of peripheral venous blood were sampled after venipuncture of the antecubitul vein under sterile conditions on the day of admission and on days 3 and 7 of hospitalization. Seven $\mathrm{ml}$ were centrifuged and serum was stored in $-80^{\circ} \mathrm{C}$ until assayed for sTREM-1. Three ml were collected into EDTA-coated tubes (Vacutainer, BD) for estimation of nTREM-1 and mTREM-1 expression. Briefly, red blood cells were lysed by ammonium chloride. White blood cells were labelled by phycoerythrin-conjugated anti-TREM-1 monoclonal 
antibodies (R\&D InC, Minneapolis, USA) for 30 minutes in the dark. nTREM-1 and mTREM-1 expression were assessed after passage of labelled cells through a flow cytometer (Epics XL/MSL, Beckman-Coulter Co, Miami Florida) and expressed as the mean fluorescence intensity (MFI) with gating for neutrophils and for monocytes by their characteristic FS/SS scattering.

Determination of sTREM-1 was performed in duplicate by a developmental enzyme-linked immunoabsorbent assay according to the instructions of the manufacturer (R\&D Inc, Minneapolis, USA). The lower detection limit and inter-day variation of the assay were $15.1 \mathrm{pg} / \mathrm{ml}$ and $5.23 \%$ respectively.

Measurement of serum CRP was performed by an immunoturbidimetric assay on Roche automated clinical chemistry analyzers and was expressed in $\mathrm{mg} / \mathrm{ml}$. CRP was used as a comparator due to its universal application in all studies of evaluation of biomarkers.

\section{Statistical analysis}

Asumming that measured parameters between groups A and B differed by $50 \%$, it was calculated that 30 to 40 patients should be assigned into each group to yield a difference at the $5 \%$ level with $80 \%$ power.

Values for nTREM-1, mTREM-1 and CRP are presented as mean $\pm \mathrm{SE}$; those of sTREM-1 are presented as medians and 95\% confidence intervals (CI) or interquartile range (IQR). Comparisons between groups for nTREM-1, mTREM-1 expression and for CRP were done by ANOVA, followed by the Tukey's test for multiple comparisons. Comparisons of sTREM-1 between groups were done by Mann-Whitney U test after Bonferroni corrections for multiple comparisons. Comparisons of sTREM-1 between consecutive days within one group were done by Wilcoxon's signed rank test. Receiver Operator Curves (ROC) were designed to asses sensitivity, specificity, positive and negative predictive values for the estimated parameters to disclose infectious from non-infectious infiltrates. Patients were divided into two categories according to serum levels of sTREM-1 upon admission: those with STREM-1 below or equal to $180 \mathrm{pg} / \mathrm{ml}$; and those with serum sTREM-1 greater than $180 \mathrm{pg} / \mathrm{ml}$. This concentration has been proposed as a threshold defining final prognosis in septic populations [22,29]. Since CAP is a common cause of sepsis, this threshold was considered of merit. Survival was assessed by Kaplan-Meier and comparisons were done by log-rank test. Correlations between severity scores and measured parameters were done according to Spearman. Probability values less than 0.05 were considered statistically significant. All statistics and graphs were done using the Statistical Package for the Social Sciences software version 17.0.0 (SPSS Inc, Chicago, IL).

\section{Results}

The study flow-chart is shown in Figure 1. Demographic and clinical data of the patients are summarized in Table 1. Patients suffering from tuberculosis and enrolled in group $B$ were presented with pleuritis.

Group A ( $\mathrm{n}=34)$ consisted of patients with community acquired pneumonia (CAP) likely to be caused by extracellural bacteria. Seventeen had microbiological evidence of pulmonary infection, with isolation of the offending pathogens from sputum, blood or BAL samples (when bronchoscopy was performed). Seventeen patients were diagnosed with CAP on the basis of typical clinical and radiological presentation and good response to antibiotic therapy. Main radiological

Total assessed for eligibility $=102$

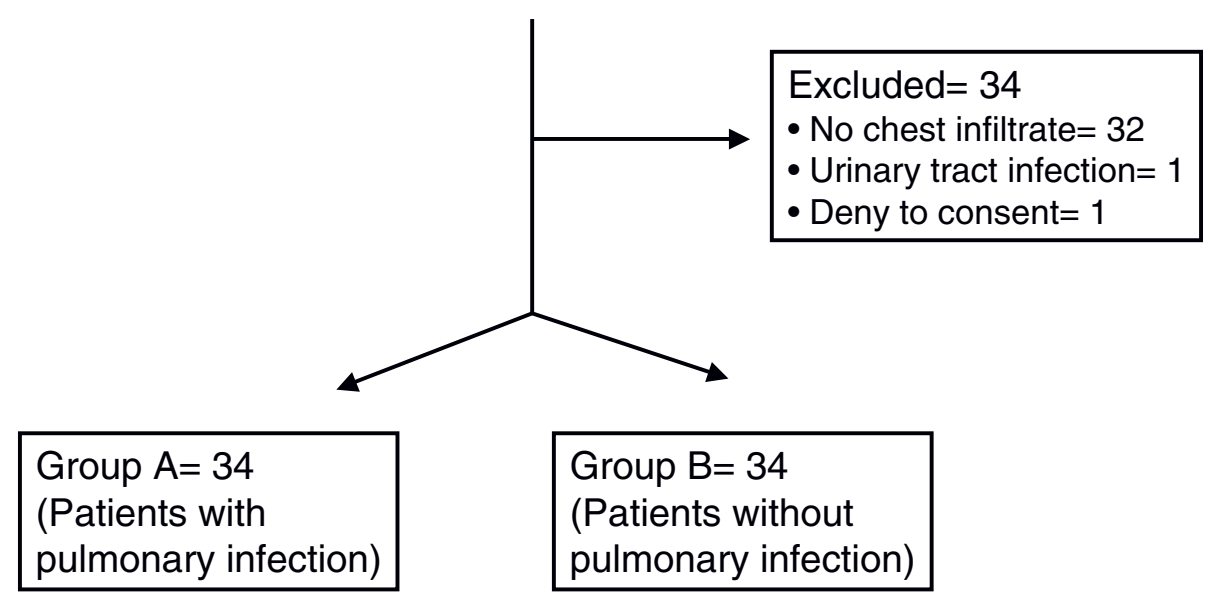

Figure 1 Randomization chart of the study. 
Table 1 Demographic and clinical characteristics of 68 patients enrolled in the study

\begin{tabular}{|c|c|c|c|}
\hline & Group A $(n=34)$ & Group B $(n=34)$ & $P$ \\
\hline Age, (years, mean $\pm \mathrm{SD}$ ) & $60.44 \pm 3.58$ & $65.83 \pm 3.04$ & $<0.001$ \\
\hline Male/female & $19 / 15$ & $21 / 13$ & ns \\
\hline \multirow[t]{6}{*}{ Diagnoses (n) } & CAP (34) & $\cdot$ TB (2) & - \\
\hline & - Streptococcus pneumoniae (4) & - Lung cancer (13) & \\
\hline & - Staphulococcus aureus (3) & • Pulmonary embolism (6) & \\
\hline & - Haemophilus influenzae (2) & - Congestive heart failure (5) & \\
\hline & - Pseudomonas aeruginosa (2) & - Interstitial lung disease (6) & \\
\hline & - Other (4) & - Other (2) & \\
\hline $\mathrm{pO}_{2} / \mathrm{FiO}_{2}$ (mean $\left.\pm \mathrm{SE}\right)$ & $240.18 \pm 20.8$ & $314.83 \pm 15.9$ & 0.006 \\
\hline SOFA (mean \pm SE) & $3.11 \pm 0.43$ & $1.66 \pm 0.18$ & 0.004 \\
\hline APACHE II (mean \pm SE) & $12.69 \pm 1.06$ & $9.4 \pm 1.09$ & 0.037 \\
\hline CPIS (mean \pm SE) & $5.38 \pm 0.23$ & $2.06 \pm 0.25$ & $<0.001$ \\
\hline Mortality [n (\%)] & $9(26)$ & $2(5.8)$ & \\
\hline $\begin{array}{l}\text { White blood cells } \\
\text { (mean } \pm \text { SE) }\end{array}$ & $14172.4 \pm 1314.7$ & $10470 \pm 874.2$ & 0.023 \\
\hline
\end{tabular}

findings were right pulmonary infiltrate (10 patients); left pulmonary infiltrate (nine patients); and bilateral lung infiltrates (eight patients). Moreover, one patient presented with left pleural effusion; four patients had both right pulmonary infiltrate and right pleural effusion; and two patients had both left lung infiltrate and left pleural effusion.

Group B ( $\mathrm{n}=34)$ consisted of patients with non-bacterial respiratory disorders. Diagnoses were: lung cancer (13 patients); pulmonary embolism (six patients); interstitial lung disease (six patients); heart failure $(n=5)$; pulmonary tuberculosis (two patients); rheumatoid pleuritis (one patient); and Q-fever (one patient). Main radiological findings were: right pulmonary infiltrate (six patients); left pulmonary infiltrate (three patients); bilateral pulmonary infiltrates (11 patients); right pleural effusion (four patients); left pleural effusion (one patient); both right lung infiltrate and right pleural effusion (four patients); both left lung infiltrates and left pleural effusion (two patients); bilateral pulmonary infiltrates and left pleural effusion (one patient); and left pulmonary infiltrate and bilateral pleural effusions (one patient).

Among patients from group A with CAP nine $(n=9)$ died; six patients were admitted to the ICU and three were not admitted to the ICU due to relatives' denial. Mean age of patients not admitted to ICU was 80 years; the first two patients had a case-history of stroke and chronic heart failure; the third patient had a case-history of lung cancer. All three died from severe sepsis and multiorgan dysfunction syndrome (MODS). Mean age of patients admitted to ICU was 70 years; two patients had a case-history of aortic valve stenosis; two patients were under chronic intake of receiving corticosteroids; the fifth patient suffered from end-stage renal disease; and the sixth patient was suffering from hepatic failure due to alcohol intake. All six patients died from severe sepsis and multiorgan dysfunction syndrome (MODS). All patients in the ICU accomplished the clinical and radiological criteria for acute respiratory distress syndrome (ARDS) and were ventilated with the strategy of low tidal volume ventilation, according to current guidelines [30], with volume limited mode ventilation, low tidal volumes (about $6 \mathrm{ml} / \mathrm{kg}$ ideal body weight), a maximum of 25-30 breaths per minute, high positive end-expiratory pressure (PEEP $10 \mathrm{cmH}_{2} \mathrm{O}$ ) and a goal plateau airway pressure $<30 \mathrm{cmH}_{2} \mathrm{O}$. Among patients admitted in the ICU, two died on the second day post-admission; one died on the third day post-admission; one on the seventh day post-admission; one the eighth day postadmission; and one on the twentieth day post admission.

Concentrations of sTREM-1 and of CRP in sera of both groups and expression of nTREM-1 and mTREM-1 are given in Table 2. All four parameters were significantly greater in group A than group $\mathrm{B}$.

ROC of sTREM-1, nTREM-1, m-TREM-1 and CRP to differentiate whether a chest X-ray infiltrate is due to CAP or to a non-infectious process is shown in Figure 2. Area under curve (AUC) of sTREM-1 was $0.771 \pm$ 0.068 (95\%CI: $0.63-0.9, \mathrm{p}=0.001)$. Sensitivity and specificity to diagnose between a pulmonary infiltrate of infectious origin and a pulmonary infiltrate of non-infectious origin were $82.6 \%$ and $63 \%$ respectively at concentrations above $19.53 \mathrm{pg} / \mathrm{ml}$. AUC of nTREM-1 and mTREM-1 were $0.778 \pm 0.063$ (95\%CI: $0.65-0.9, \mathrm{p}=$ 0.001 ) and $0.712 \pm 0.07$ (95\%CI: $0.56-0.86, \mathrm{p}=0.009$ ) respectively. Sensitivity and specificity to diagnose between a pulmonary infiltrate of infectious origin and a pulmonary infiltrate of non-infectious origin were $78.3 \%$ and $58.6 \%$ for nTREM-1 above 2.55 MFI. Sensitivity and 
Table 2 Concentrations of soluble triggering receptor expressed on myeloid cells-1 (sTREM-1) and of C-reactive protein (CRP) in the sera and expression of TREM-1 on neutrophils and on monocytes of 68 patients with pulmonary infiltrates $^{\S}$

\begin{tabular}{|c|c|c|c|c|c|c|}
\hline & Survivors & Non-Survivors & $\mathrm{p}$ & Group A & Group B & $\mathrm{p}$ \\
\hline & \multicolumn{6}{|c|}{ sTREM-1 (pg/ml, median-IQR) } \\
\hline$\overline{\text { Day1 }}$ & $28.13(95.00)$ & $189.61(204.99)$ & 0.028 & $102.09(227.21)$ & $<15.10(31.04)$ & $<0.0001$ \\
\hline Day3 & $<15.10(39.45)$ & $122.80(231.05)$ & 0.065 & $28.12(263.74)$ & $<15.10(21.10)$ & 0.010 \\
\hline \multirow[t]{2}{*}{ Day 7} & $<15.10(35.60)$ & $52.30(225.81)$ & 0.055 & $12.96(202.89)$ & $<15.10(18.80)$ & 0.022 \\
\hline & \multicolumn{6}{|c|}{ TREM-1 on neutrophils ( $\mathrm{MFI}$, mean $\pm \mathrm{SE}$ ) } \\
\hline Day1 & $3.55 \pm 0.53$ & $4.18 \pm 1.07$ & $N S^{*}$ & $4.67 \pm 0.53$ & $2.64 \pm 0.25$ & 0.001 \\
\hline Day3 & $2.26 \pm 0.25$ & $3.40 \pm 1.10$ & NS & $3.14 \pm 0.37$ & $1.57 \pm 0.20$ & NS \\
\hline \multirow[t]{2}{*}{ Day 7} & $1.46 \pm 0.31$ & $2.34 \pm 0.95$ & NS & $1.20 \pm 0.37$ & $1.60 \pm 0.43$ & NS \\
\hline & \multicolumn{6}{|c|}{ TREM-1 on monocytes (MFI, mean \pm SE) } \\
\hline Day1 & $3.24 \pm 0.31$ & $4.51 \pm 0.91$ & NS & $4.2 \pm 0.42$ & $2.64 \pm 0.35$ & 0.007 \\
\hline Day3 & $2.02 \pm 0.33$ & $3.42 \pm 0.57$ & NS & $1.50 \pm 0.20$ & $2.20 \pm 0.43$ & 0.001 \\
\hline \multirow[t]{2}{*}{ Day 7} & $2.35 \pm 0.25$ & $4.25 \pm 1.45$ & NS & $1.76 \pm 0.20$ & $3.21 \pm 0.43$ & 0.003 \\
\hline & \multicolumn{6}{|c|}{$\mathrm{CRP}(\mathrm{mg} / \mathrm{dl}$, mean $\pm \mathrm{SE})$} \\
\hline$\overline{\text { Day } 1}$ & $11.6 \pm 1.5$ & $16.6 \pm 3.8$ & NS & $18.03 \pm 2$ & $7.1 \pm 1.5$ & $<0.001$ \\
\hline Day3 & $9.4 \pm 1.4$ & $12.3 \pm 2.7$ & NS & $12.2 \pm 2.0$ & $7.1 \pm 1.5$ & 0.05 \\
\hline Day 7 & $6.4 \pm 1.1$ & $9.7 \pm 3.5$ & NS & $7.2 \pm 1.5$ & $6.2 \pm 1.6$ & NS \\
\hline
\end{tabular}

*NS: non significant

${ }^{5}$ Patients are divided into two groups; survivors and non-survivors; and into those with community-acquired pneumonia (group A) and into those with an infiltrate of non-infectious origin (group B).

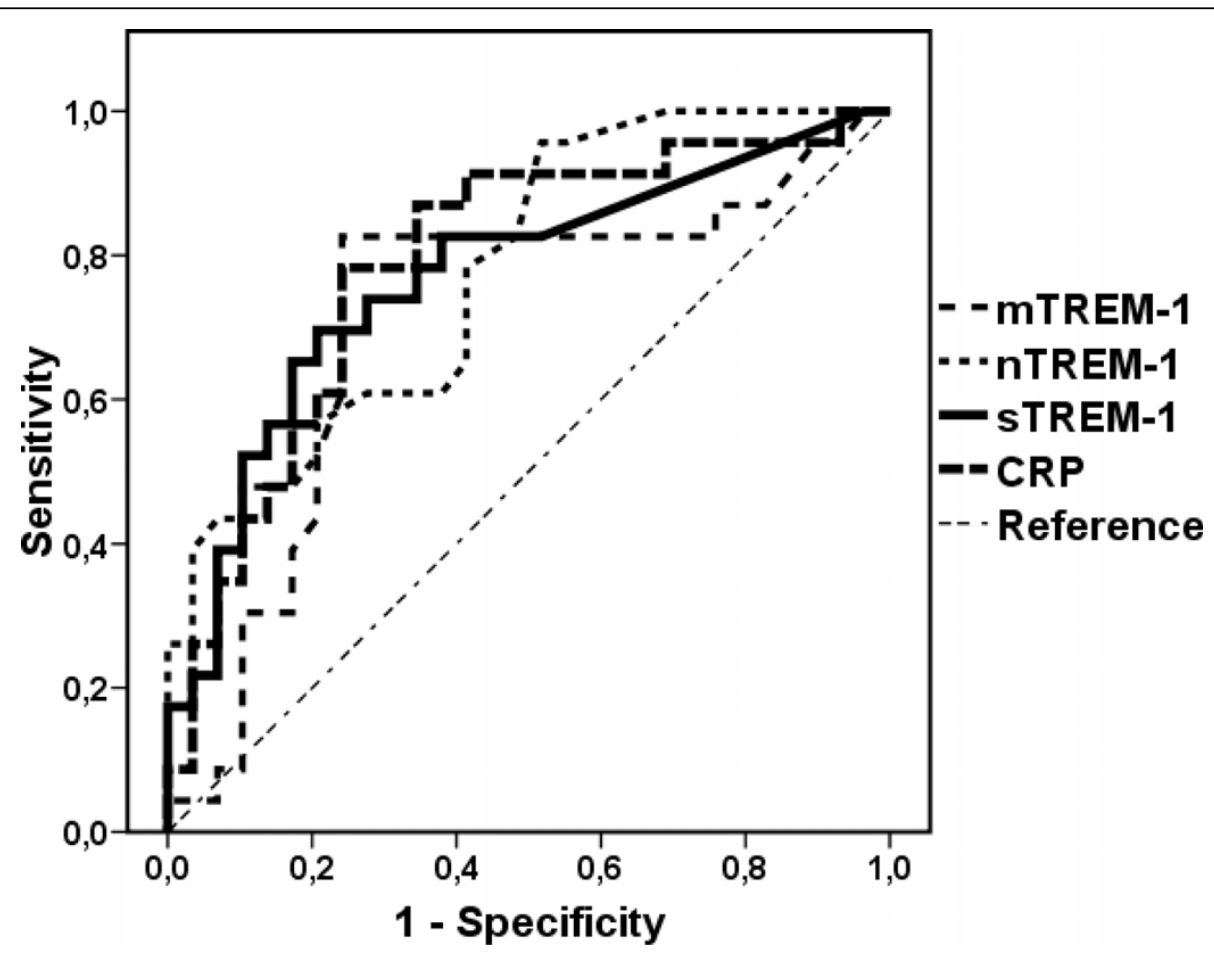

Figure 2 Receiver operator curves (ROC) of serum STREM-1, of TREM-1 expressed on neutrophils (nTREM-1), of TREM-1 expressed on monocytes (mTREM-1) and of serum CRP to discriminate between a pulmonary infiltrate of bacterial origin from a pulmonary infiltrate of non-bacterial origin. 
specificity to diagnose between a pulmonary infiltrate of infectious origin and a pulmonary infiltrate of non-infectious origin were $82.6 \%$ and $75.9 \%$ respectively for mTREM-1 above 3.05 MFI. AUC of CRP was $0.789 \pm$ $0.065(95 \% \mathrm{CI}: 0.66-0.9, \mathrm{p}<0.001)$. Sensitivity and specificity to diagnose between a pulmonary infiltrate of infectious origin and a pulmonary infiltrate of non-infectious origin were $78 \%$ and $76 \%$ respectively at concentrations above $8.7 \mathrm{mg} / \mathrm{ml}$.

Positive correlations were found between APACHE II scores and expression of TREM-1 on monocytes on day $1\left(\mathrm{r}_{\mathrm{s}}:+0.363\right.$, p: 0.010); and between APACHE II scores and sTREM-1 on day $1\left(\mathrm{r}_{\mathrm{s}}:+0.262\right.$, p: 0.043). No significant correlations were found between APACHE II scores and expression of TREM-1 on neutrophils on day 1 as well as between SOFA scores and any of the measured parameters on day 1 .
Correlations between serum levels of sTREM-1 and CRP and expression of TREM-1 on monocytes and neutrophils in relation to the identified causative pathogen of CAP are shown in Figure 3. Serum levels of sTREM1 were greater among patients with CAP caused by Gram (+) cocci and Haemophilus influenzae than among patients with CAP caused by other pathogens.

Death occurred in three out of 17 patients were no pathogen was defined (17.6\%); in nil out of three patients infected by atypical pathogens $(0 \%)$; in three out of seven patients (42.9\%) infected by Gram-negative bacteria; and in three out of nine patients (33.3\%) infected by Gram-positive cocci or H. influenzae (p: 0.034 between grouping according to pathogen). Survival of patients with sTREM-1 on day 1 below or equal to $180 \mathrm{pg} / \mathrm{ml}$ was prolonged compared with patients with sTREM-1 on day 1 above $180 \mathrm{pg} / \mathrm{ml}$ (Figure 4).
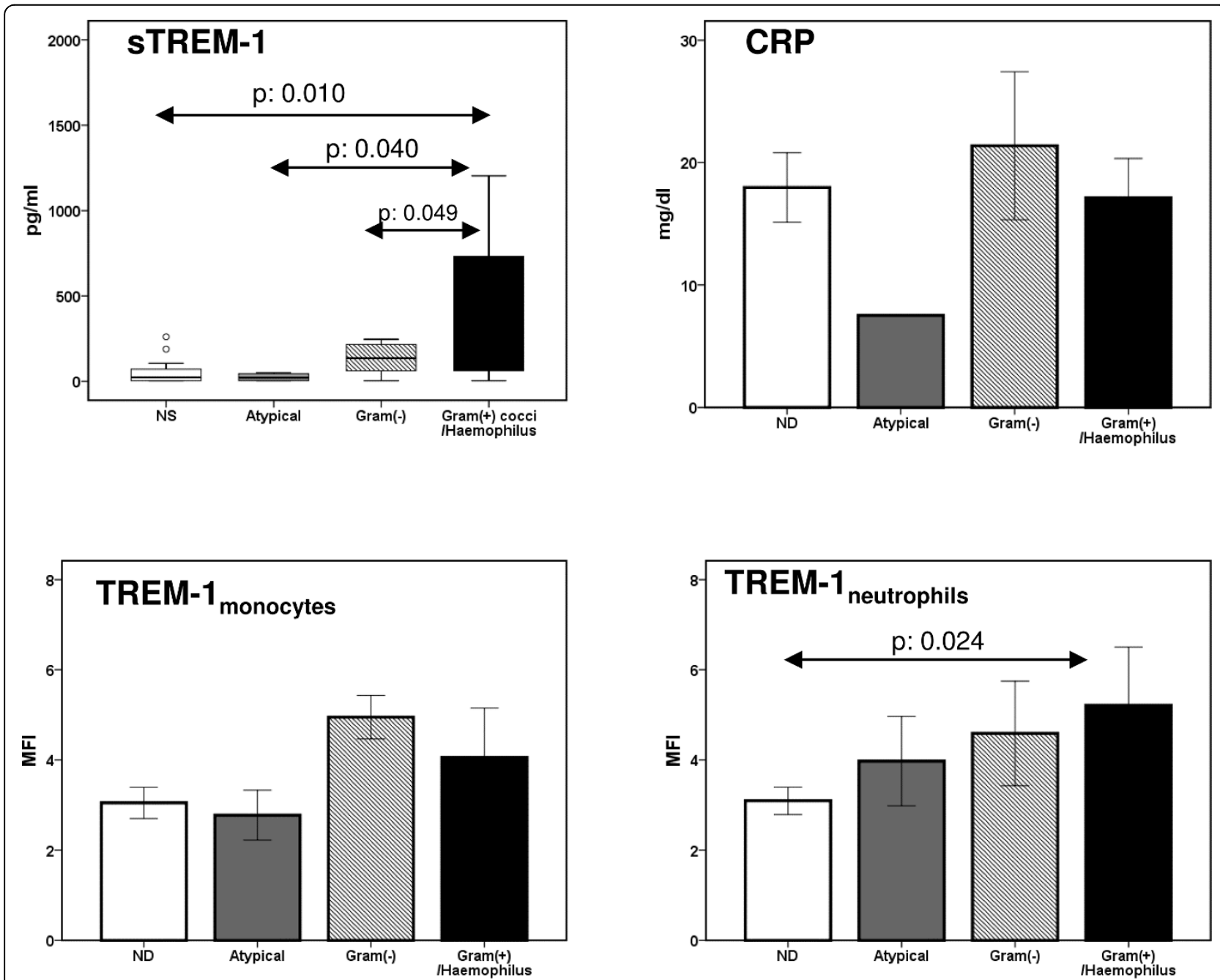

Figure 3 Concentrations of STREM-1 and of CRP in serum and expression of TREM-1 on monocytes and on neutrophils on the first day of acute respiratory illness of patients with new consolidation in chest X-ray. Results are given as box plots for sTREM-1 and as means \pm SE for the other parameters. ND: not defined. Statistically significant comparisons are indicated. 


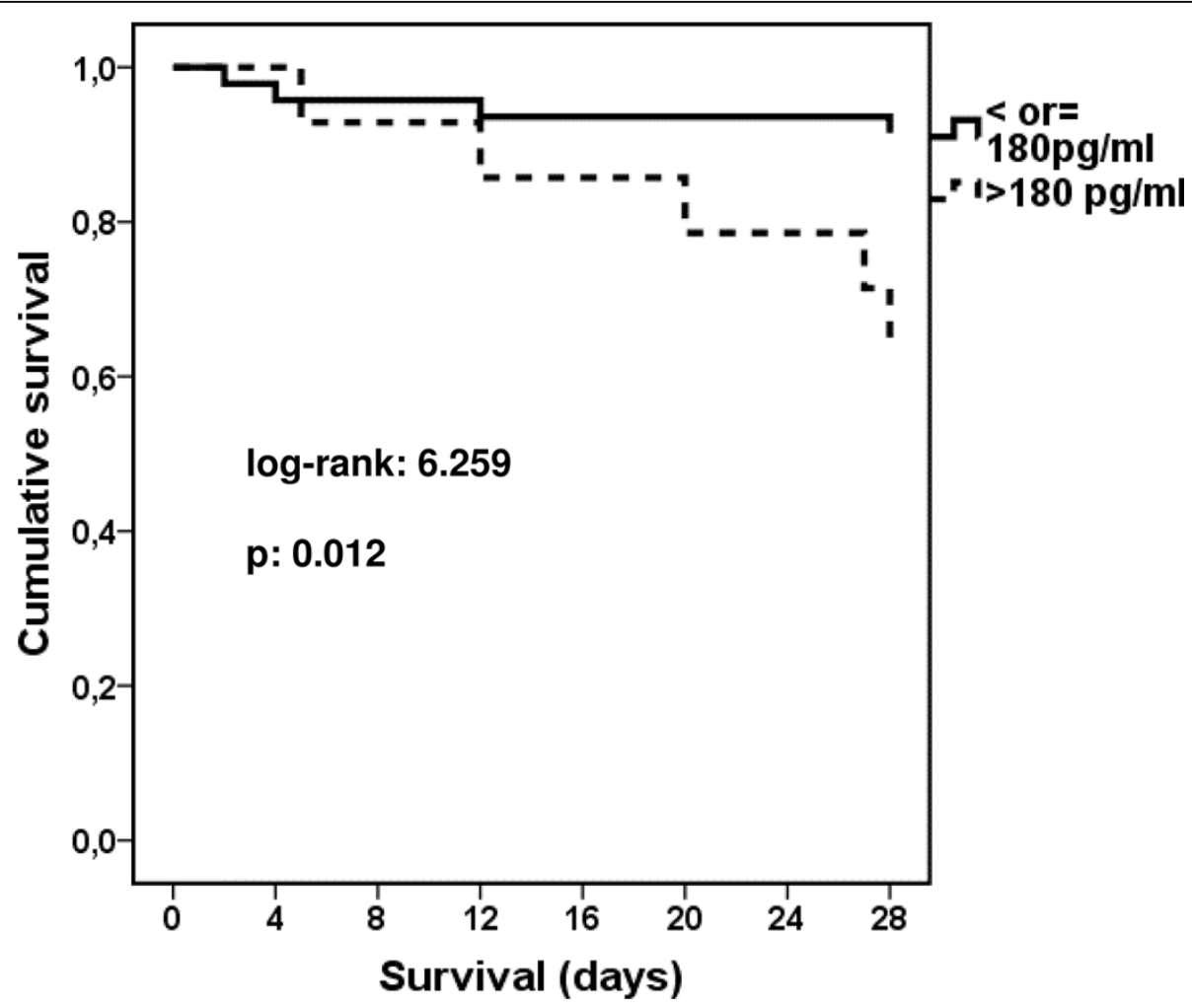

Figure 4 Survival of patients with acute respiratory illness and with new consolidation in chest X-ray in relation to serum concentration of STREM-1 on day 1 .

Concentrations of sTREM-1 and CRP in serum and expression of nTREM- and of mTREM-1 on days 3 and 7 are shown in Table 2. Estimated parameters were greater in group A than in group B. Median (IQR) sTREM-1 of survivors of group A was 90.52 (398.04) $\mathrm{pg} / \mathrm{ml}$ on day 1 ; it was decreased to 17.20 (257.73) pg/ $\mathrm{ml}$ on day 3 (p: 0.012 compared with day 1 ); and it was decreased to $10.40(174.69) \mathrm{pg} / \mathrm{ml}$ on day 7 (p: 0.007 compared with day 1). Median (IQR) sTREM-1 of nonsurvivors of group A was $189.61(186.73) \mathrm{pg} / \mathrm{ml}$ on day 1 ; it was unchanged on day 3 [144.07 (258.10) pg/ml; p: NS compared with day 1]; and it was unchanged on day 7 [59.03 (272.96) pg/ml, p: NS compared with day 1].

\section{Discussion}

The results of the present study indicate that TREM-1 can be used as marker of bacterial infection in patients with lung infiltrates. sTREM-1, nTREM-1, mTREM-1 and CRP were comparable to their discriminating ability between a pulmonary infiltrate of infectious origin and a pulmonary infiltrate of non-infectious origin. sTREM-1 levels were decreased within the first 48 hours in patients with CAP with favourable outcome probably after the initiation of appropriate therapy followed by improvement of clinical symptoms. Finally, sTREM-1 levels above $180 \mathrm{pg} / \mathrm{ml}$ were an accurate independent predictor of in-hospital mortality from CAP.

Discrimination of the infectious or non-infectious origin of a pulmonary infiltrate remains an everyday clinical problem. CPIS was introduced for that purpose helping considerable in cases of ventilator-associated pneumonia (VAP) [23]. TREM-1 is a surface receptor on cells of the myeloid lineage. Activation of TREM-1 leads to the production of pro-inflammatory cytokines $[9,31,32]$. Binding of its ligand is possibly linked to the activation of several transcription complexes that synergize with NF- $\kappa \mathrm{B}$ in order to elicit transcription of genes of pro-inflammatory cytokines [8]. sTREM-1 is the soluble counterpart of TREM-1 and it is probably shed in the systemic circulation from cell membranes of neutrophils and monocytes [7,33,34]. The physiologic role of sTREM-1 remains under question despite data support a probable anti-inflammatory role $[31,35]$.

TREM-1 has been studied in patients with pneumonia, especially VAP $[5,21,36-38]$. Few data are available on the diagnostic role of TREM-1 and of sTREM-1 in patients with lung infiltrates. Our data are in agreement with observations from the study by Phua [36]. Their proposed sTREM-1 cut-off point was $163 \mathrm{ng} / \mathrm{ml}$, which is different than the one we found. This may be result 
from the different method of assaying sTREM-1 the used being Western blotting.

The results of our study are in contrast to those of another study [37] that did not disclose any difference in nTREM-1 expression between patients with and without a bacterial lung infection probably due to the small number of patients included in that former study. El Sohl et al [38] reported elevated alveolar levels of sTREM-1 in pulmonary aspiration syndromes, but not in serum. However, serial plasma sTREM-1 levels were not obtained and the possibility that plasma levels might rise on subsequent days cannot be excluded.

Two recent studies $[39,40]$ evaluated the diagnostic role of CPIS and of sTREM-1 in BAL fluid from patients with bilateral lung infiltrates in the intensive care unit (ICU). These studies reported controversial results. However authors did not measure sTREM-1 in serum on consecutive days.

The reported results of the present study are the first to our knowledge that evaluate the diagnostic value of TREM-1 among patients with lung infiltrates to discriminate CAP. They also disclose a relationship between levels of circulating STREM-1 and causative pathogens. More precisely, infections caused by Streptococcus pneumoniae, Sthaphylococcus aureus and Haemophilus influenzae were accompanied by greater levels of STREM-1 and by greater expression of TREM-1 on neutrophils than infections caused by other pathogens. Although it may be hypothesized that Gram-positive cocci and $H$. influenzae are strong inducers of TREM-1 expression, it should be emphasized that TREM-1 is one PRR, the exact agonist of which remains to be found [29,31].

A former study of our group [29] and another by Gibot et al [22] in heterogeneous populations of patients with severe sepsis of diverse aetiology investigated the role of early assessment of sTREM- 1 as a determinant of final outcome. Results revealed that concentrations greater than $180 \mathrm{pg} / \mathrm{ml}$ are accompanied by survival benefit. The exactly opposing finding is reported here. This discrepancy may be explained by the enrolment of more homogeneous populations of patients, compared to these former studies [22,29], all suffering with CAP.

Our study presents two main limitations: a) no documented cases of CAP by Legionella pneumophila, Mycoplasma pneumoniae, protozoa or parasites were enrolled in group A; b) mortality in the CAP patient group was high probably due to the existence of severe co-morbid conditions.

\section{Conclusions}

In conclusion, the presented results indicate that serum STREM-1 and expression of TREM-1 on neutrophils and monocytes may serve as markers of CAP in patients with pulmonary infiltrates. Concentrations of STREM-1 in serum are particularly increased in CAP caused by Gram-positive cocci and Haemophilus species. The real clinical value of sTREM-1 assay comes when TREM-1 levels are low, allowing the clinician to withhold empiric antibiotics until culture results are available, and thus eliminating unnecessary antibiotic exposure to the patient. And finally, early serum levels of sTREM-1 greater than $180 \mathrm{pg} / \mathrm{ml}$ in CAP are associated with unfavourable prognosis.

\begin{abstract}
Acknowledgements
Funding Source: None

The present authors would like to thank all patients who participated in the current study, the doctors and nurses of the Department of Critical Care and Pulmonary Services, National and Kapodistrian University of Athens, 'Evangelismos' Hospital, Athens, Greece for their hand work in the treatment of the patients and the doctors and laboratory personnel of the $4^{\text {th }}$ Department of Internal Medicine, National and Kapodistrian University of Athens, 'Attikon' Hospital, Athens, Greece for their most helpful support during the study. Finally, the current authors thank Paris Praxitelous Vogazianos (Assistant Professor of Mathematics and Statistics, Americanos College, Nicosia, Cyprus) for his help in statistical analysis of the manuscript.
\end{abstract}

\section{Author details}

${ }^{1}$ Department of Critical Care and Pulmonary Services, National and Kapodistrian University of Athens, 'Evangelismos' Hospital, Athens, Greece. ${ }^{2} 4$ th Department of Internal Medicine, National and Kapodistrian University of Athens, 'Attikon' Hospital, Athens, Greece. ${ }^{3}$ 2nd Pulmonary Department, National and Kapodistrian University of Athens, 'Attikon' Hospital, Athens, Greece.

\section{Authors' contributions}

IP participated in the study design, the enrolment of patients, the estimation of TREM-1, sTREM-1, CRP, the follow-up of patients and wrote the manuscript.

DP participated in the study design and in the estimation of TREM- 1 and sTREM-1.

VK carried out the estimation of TREM-1.

AK and SAP participated in study design, and drafted the manuscript. HG participated in study design and drafted the manuscript EJGB coordinated the lab job, analyzed the data and drafted the manuscript. All authors read and approved the final manuscript.

\section{Authors' information}

IP is a MD in the Department of Critical Care and Pulmonary Services, National and Kapodistrian University of Athens, in 'Evangelismos' Hospital, Athens. DP is MD in the $4^{\text {th }}$ Department of Internal Medicine, National and Kapodistrian University of Athens, in 'Attikon' Hospital, Athens. VK is a MD of the $4^{\text {th }}$ Department of Internal Medicine, National and Kapodistrian University of Athens, in 'Attikon' Hospital, Athens. AK is an Assistant Professor MD in the Department of Critical Care and Pulmonary Services, National and Kapodistrian University of Athens, in 'Evangelismos' Hospital, Athens and expert in the management of critically ill patients. SAP is Assistant Professor $\mathrm{MD}$ in the $2^{\text {nd }}$ Pulmonary Department, National and Kapodistrian University of Athens, in 'Attikon' Hospital, Athens, Greece and expert in the field of respiratory diseases. $\mathrm{HG}$ is a Professor MD in the $4^{\text {th }}$ Department of Internal Medicine, National and Kapodistrian University of Athens, in 'Attikon' Hospital, Athens and expert in the field of infections and sepsis. And finally EJGB is an Assistant Professor MD in the $4^{\text {th }}$ Department of Internal Medicine, National and Kapodistrian University of Athens, in 'Attikon' Hospital, Athens and expert in respiratory infections and sepsis management.

\section{Competing interests}

Actual or potential conflict of interest: None. All the authors, llias Porfyridis MD, Diamantis Plachouras MD, Vasiliki Karagianni MD, Anastasia Kotanidou Ass. Prof. MD, Spyridon A Papiris Ass. Prof. MD, Helen Giamarellou Prof. MD 
and Evangelos J. Giamarellos-Bourboulis Ass. Prof. MD have no conflicts of interest to disclose related to this study. Evangelos J. Giamarellos-Bourboulis Prof. MD has received reimbursement for attending the $29^{\text {th }}$ International Symposium on Intensive Care and Emergency Medicine where participated as a speaker and unrestricted educational grants from ABBOTT Hellas SA; Wyeth Hellas SA; Sanofi-Aventis Hellas SA.

Received: 29 March 2010 Accepted: 29 September 2010

Published: 29 September 2010

\section{References}

1. Franquet T: Imaging of pneumonia: trends and algorithms. Eur Respir $J$ 2001, 18:196-208.

2. Muller B, Harbarth S, Stolz D, Binqisser R, Mueller C, Leuppi J, Nusbaumer C, Tamm M, Christ-Crain Ml: Diagnostic and prognostic accuracy of clinical and laboratory parameters in community-acquired pneumonia. BMC Infect Dis 2007, 7:10

3. Colonna M, Facchetti F: TREM-1 (triggering receptor expressed on myeloid cells): a new player in acute inflammatory responses. J Infect Dis 2003, 187:397-401

4. Bouchon A, Facchetti F, Weigand MA, Colonna M: TREM-1 amplifies inflammation and is a crucial mediator of septic shock. Nature 2001, 410:1103-7.

5. Routsi C, Giamarellos-Bourboulis EJ, Antonopoulou A, Kollias S, Siasiakou S, Koronaios A, Zakynthinos S, Armaganidis A, Giamarellou H, Roussos C: Does soluble triggering receptor expressed on myeloid cells-1 play any role in the pathogenesis of septic shock? Clin Exp Immunol 2005, 142:62-67.

6. Gibot S, Cravoisy A, Levy B, Bene MC, Faure G, Bollaert PE: Soluble triggering receptor expressed on myeloid cells and the diagnosis of pneumonia. N Engl J Med 2004, 350:451-8.

7. Dimopoulou I, Orfanos SE, Pelekanou A, Kotanidou A, Livaditi O, Augustatou C, Zervou M, Douka E, Theodorakopoulou M, Karagianni V, Douzinas E, Armaganidis A, Giamarellos-Bourboulis EJ: Serum of patients with septic shock stimulates the expression of Trem-1 on U937 monocytes. Inflamm Res 2009, 58:127-32.

8. Gibot S: Clinical review: Role of triggering receptor expressed on myeloid cells-1 during sepsis. Critical Care 2005, 9:485-489.

9. Wong-Baeza I, González-Roldán N, Ferat-Osorio E, Esquivel-Callejas N, Aduna-Vicente R, Arriaga-Pizano L, Astudillo-de la Vega H, VillasisKeever MA, Torres-González R, Estrada-García I, López-Macías C, Isibasi A: Triggering receptor expressed on myeloid cells-1 (TREM-1) is regulated post-transcriptionally and its ligand is present in the sera of some septic patients. Clin Exp Immunol 2006, 145:448-455.

10. Determann RM, Weisfelt M, de Gans J, van der Ende A, Schultz MJ, van de Beek D: Soluble triggering receptor expressed on myeloid cells-1: a biomarker for bacterial meningitis. Intensive Care Med 2006, 32:1243-7.

11. Yasuda T, Takeyama Y, Ueda T, Shinzeki M, Sawa H, Takahiro N, Kamei K, $\mathrm{Ku} Y$, Kuroda $Y$, Ohyanagi $\mathrm{H}$ : Increased levels of soluble triggering receptor expressed on myeloid cells-1 in patients with acute pancreatitis. Crit Care Med 2008, 36:2048-2053.

12. Ferat-Osorio E, Wong-Baeza I, Esquivel-Callejas N, Figueroa-Figueroa S, Duarte-Rojo A, Guzmán-Valdivia-Gómez G, Rodea-Rosas H, TorresGonzález R, Sánchez-Fernández P, Arriaga-Pizano L, López-Macías C, RoblesDíaz G, Isibasi A: Triggering receptor expressed on myeloid cells-1 expression on monocytes is associated with inflammation but not with infection in acute pancreatitis. Crit Care 2009, 14:R69.

13. Koussoulas V, Vassiliou S, Demonakou M, Tassias G, Giamrellos-Bourboulis EJ, Mouktaroudi M, Giamarellou H, Barbatzas C: Soluble triggering receptor expressed on myeloid cells-1(STREM-1): a new mediator involved in the pathogenesis of peptic ulcer disease. Eur I Gastroenterol Hepatol 2006, 18:375-9.

14. Tzivras M, Koussoulas V, Giamarellos-Bourboulis EJ, Tzivras D, Tsaganos T, Koutoukas $P$, Giamarellou $H$, Archimandritis A: Role of soluble triggering receptor expressed on myeloid cells-1 in inflammatory bowel disease. World J Gastroenterol 2006, 12:3416-9.

15. Ho CC, Liao WY, Wang CY, Lu YH, Huang HY, Chen HY, Chan WK, Chen HW, Yang PC: TREM-1 expression in tumor-associated macrophages and clinical outcome in lung cancer. Am J Respir Crit Care Med 2008, 177:763-770.

16. Mohamadzadeh $M$, Coberley SS, Olinger GG, Kalina WW, Ruthel G, Fuller $C L$, Swenson DL, Pratt WD, Kuhns DB, Schmaljohn AL: Activation of triggering receptor expressed on myeloid cells-1 on human neutrophils by Marburg and ebola viruses. J Virol 2006, 80:7235-44.

17. Radsak MP, Taube C, Haselmayer P, Tenzer S, Salih HR, Wiewrodt R, Buhl R, Schild $H$ : Soluble triggering receptor expressed on myeloid cells 1 is released in patients with stable chronic obstructive pulmonary disease. Clin Dev Immunol 2007, 2007:52040.

18. Adib-Conquy M, Monchi M, Goulenok C, Laurent I, Thuong M, Cavaillon JM, Adrie C: Increased plasma levels of soluble triggering receptor expressed on myeloid cells 1 and procalcitonin after cardiac surgery and cardiac arrest without infection. Shock 2007, 28:406-10.

19. Ferat-Osorio E, Esqivel-Callejas N, Wong-Baeza I, Aduna-Vicente R, ArriagaPizano L, Sánchez-Fernández P, Torres-Gonzáles R, López-Macías C, Isibasi A: The increased expression of TREM-1 on monocytes is associated with infectious and non-infectious inflammatory processes. J Surg Res 2008, 150:110-117.

20. Bopp C, Hofer S, Bouchon A, Zimmermann JB, Martin E, Weigand MA: Soluble TREM-1 is not suitable for distinguishing between systemic inflammatory response syndrome and sepsis survivors and nonsurvivors in the early stage of acute inflammation. Eur J Anaesthesiol 2009, 26:504-7.

21. Tejera A, Santolaria F, Diez ML, Aleman-Valls MR, Gonzalez-Reimers E, Martinez-Riera A, Milena-Abril A: Prognosis of community acquired pneumonia(CAP): value of triggering receptor expressed on myeloid cells-1 (TREM-1) and other mediators of the inflammatory response. Cytokine 2007, 38:117-23.

22. Gibot S, Cravoisy A, Kolopp-Sarda MN, Béné MC, Faure G, Bollaert PE: Timecourse of STREM (soluble triggering receptor expressed on myeloid cells)-1, procalcitonin, and C-reactive protein plasma concentrations during sepsis. Crit Care Med 2005, 33:792-796.

23. Fartoukh M, Maitre B, Honoré S, Cerf C, Zahar JR, Brun-Buisson C: Diagnosing pneumonia during mechanical ventilation: the clinical pulmonary infection score revisited. Am J Respir Crit Care Med 2003, 168:173-9.

24. Mandell LA, Wunderink RG, Anzueto A, Bartlett JG, Campbell GD, Dean NC, Dowell SF, File TM Jr, Musher DM, Niederman MS, Torres A, Whitney CG, Infectious Diseases Society of America; American Thoracic Society: Infectious Diseases Society of America/American Thoracic Society Consensus Guidelines on the Management of Community-Acquired Pneumonia in Adults. Clin Infect Dis 2007, 44:27-72.

25. Woodhead M, Blasi F, Ewig S, Huchon G, leven M, Ortqvist A, Schaberg T, Torres A, van der Heijden G, Verheij TJM: Guidelines for the management of adult lower respiratory track infections. Eur Respir J 2005, 26:1138-1180.

26. Tapson VF: Acute pulmonary embolism. N Engl I Med 2008, 358:1037-52.

27. Hunt SA, Abraham WT, Chin MH, Feldman AM, Francis GS, Ganiats TG, Jessup M, Konstam MA, Mancini DM, Michi K, Oates JA, Rahko PS, Silver MA, Stevenson LW, Yancy CW: 2009 focused update incorporated into the ACC/AHA 2005 guidelines for the diagnosis and management of chronic heart failure in adults: A Report of the American College of Cardiology Foundation/American Heart Association Task Force on Practice Guidelines: developed in collaboration with the International Society for Heart and Lung Transplantation. Circulation 2009, 119:391-479.

28. American Thoracic Society/European Respiratory Society international multidisciplinary consensus classification of idiopathic interstitial pneumonias. Am J Respir Crit Care Med 2002, 165:277-304.

29. Giamarellos-Bourboulis EJ, Tsaganos T, Spyridaki E, Mouktaroudi M, Plachouras D, Vaki I, Karagianni V, Antonopoulou A, Veloni V, Giamarellou H: Early changes of CD4-positive lymphocytes and NK cells in patients with severe Gram-negative sepsis. Crit Care 2006, 10:R166.

30. The National Heart, Lung, and Blood Institute ARDS Clinical Trials Network: Higher versus Lower Positive End-Expiratory Pressures in Patients with the Acute Respiratory Distress Syndrome. N Engl J Med 2004, 351:327-36.

31. Ford JW, MCVicar DW: TREM and TREM-like receptors in inflammation and disease. Curr Opin Immunol 2009, 21:38-46.

32. Klesney-Tait J, Turnbull IR, Colonna M: The TREM receptor family and signal integration. Nat Immunol 2006, 7:1266-73.

33. Plachouras D, Routsi C, Giamarellos-Bourboulis EJ, Spyridaki E, Andrianakis I, Metzelopoulos S, Tsaganos T, Floros I, Douzinas EE, Armaganidis A, Roussos C, Giamarellou H: Monocytes as a site of production of soluble triggering receptor expressed on myeloid cells -1(STREM-1) in the septic host. Scand J Infect Dis 2006, 38:909-915.

34. Gibot S, Kolopp-Sarda MN, Béné MC, Bollaert PE, Lozniewski A, Mory F, Levy B, Faure GC: Soluble triggering receptor expressed on myeloid cells- 
1 modulates the inflammatory response in murine sepsis. J Exp Med 2004, 200:1419-26.

35. Giamarellos-Bourboulis EJ, Zakynthinos S, Baziaka F, Papadomichelakis E, Virtzili S, Koutoukas P, Armaganidis A, Giamarellou H, Roussos C: Soluble triggering receptor expressed on myeloid cells-1 as an antiinflammatory mediator in sepsis. Intensive Care Med 2006, 32:237-43.

36. Phua J, Koay ESC, Zhang D, Tai LK, Boo XL, Lim KC, Lim TK: Soluble triggering receptor expressed on myeloid cells -1 in acute respiratory infections. Eur Respir J 2006, 28:695-702.

37. Richeldi L, Mariani M, Losi M, Maselli F, Corbetta L, Buonsanti C, Colonna M, Sinigaglia F, Panina-Bordignon P, Fabbri LM: Triggering receptor expressed on myeloid cells: role in the diagnosis of lung infections. Eur Respir J 2004, 24:247-50.

38. El Solh AA, Akinnusi ME, Peter M, Berim I, Schultz MJ, Pineda L: Triggering receptors expressed on myeloid cells in pulmonary aspiration syndromes. Intensive Care Med 2008, 34:1012-1019.

39. Anand NJ, Zuick S, Klensey-Tait J, Kollef MH: Diagnostic implications of soluble triggering receptor expressed on myeloid cells-1 in BAL fluid of patients with pulmonary infiltrates in the ICU. Chest 2009, 135:641-647.

40. Huh JW, Lim CM, Koh Y, Oh YM, Shim TS, Lee SD, Kim WS, Kim DS, Kim WD, Hong SB: Diagnostic utility of the soluble triggering receptor expressed on myeloid cells-1 in bronchoalveolar lavage fluid from patients with bilateral lung infiltrates. Crit Care 2008, 12:R6.

\section{Pre-publication history}

The pre-publication history for this paper can be accessed here: http://www.biomedcentral.com/1471-2334/10/286/prepub

doi:10.1186/1471-2334-10-286

Cite this article as: Porfyridis et al.: Diagnostic value of triggering receptor expressed on myeloid cells-1 and C-reactive protein for patients with lung infiltrates: an observational study. BMC Infectious Diseases 2010 10:286.

\section{Submit your next manuscript to BioMed Central} and take full advantage of:

- Convenient online submission

- Thorough peer review

- No space constraints or color figure charges

- Immediate publication on acceptance

- Inclusion in PubMed, CAS, Scopus and Google Scholar

- Research which is freely available for redistribution 